\title{
Climatic variation alters supply-side ecology: impact of climate patterns on phytoplankton and mussel recruitment
}

\author{
Bruce A. Menge, ${ }^{1}$ Francis Chan, Karina J. Nielsen, ${ }^{2}$ Emanuele Di Lorenzo, ${ }^{3}$ and Jane Lubchenco \\ Department of Zoology, Oregon State University, Corvallis, Oregon 97331-2914 USA
}

\begin{abstract}
Climate change will modify ecosystems, but a dearth of long-term data sets on critical ecological factors makes prediction of mechanistic pathways and scope for ecological changes difficult. Using 14-18 year time series of phytoplankton abundance and mussel recruitment at up to 10 sites along $320 \mathrm{~km}$ of coast in a rocky intertidal ecosystem, we examined the influence of climatic variation at 3-7 year (El Niño-Southern Oscillation [ENSO]), 7-10 year (North Pacific Gyre Oscillation [NPGO]), and 20+ year (Pacific Decadal Oscillation [PDO]) timescales. Phytoplankton and mussel recruitment revealed order-ofmagnitude increases and seasonal shifts in the 2000s compared to 1989-1999, but seasonal shifts were in opposite directions with phytoplankton blooms occurring earlier and recruitment occurring later in the year. The NPGO had the strongest relationships with both phytoplankton and recruitment, while relationships between these factors and ENSO and PDO were weak. Increases were associated with cooler ocean temperature and intensification in the ocean gyre-scale circulation reflected in a stronger North Pacific Current (NPC). Phytoplankton abundance and mussel recruitment were positively correlated, suggesting that increases in larval food may have driven the changes in mussel recruitment. With our prior demonstration that mussel growth rate is sensitive to phytoplankton concentration, these results suggest an important effect of bottom-up forcing on the dynamics of coastal mussel populations. We conclude that central supply-side ecological processes in coastal ecosystems are sensitive to long-term ocean basin-scale oceanographic and atmospheric fluctuation. Despite these changes, intertidal community dynamics have changed only in relatively subtle ways, suggesting a role for local ecological interactions in dampening the effects of dominant modes of climate forcings in coastal ecosystems.
\end{abstract}

Key words: bottom-up; climate change; El Niño-Southern Oscillation; mussels; North Pacific Gyre Oscillation; Pacific Decadal Oscillation; phytoplankton; recruitment; rocky intertidal; supply-side ecology.

\section{INTRODUCTION}

Diverse and productive coastal ecosystems, and the ecosystem services they provide (Millenium Ecosystem Assessment 2005) may be particularly sensitive to the impacts of global warming because of the tight associations between atmospheric forcing, nutrient inputs, and propagule transport in marine ecosystems (Harley et al. 2006). The fate of coastal ecosystems is of intense concern and interest not just because of this sensitivity to climate, but also due to their great economic and sociological importance to humanity. For example, concern about the impacts of anthropogenic-driven coastal hypoxia and anoxia ("dead zones"), already common around the world (Diaz 2001, Rabalais et al. 2001, Diaz and Rosenberg 2008), has recently been heightened by the discovery of new hypoxic/anoxic

Manuscript received 12 November 2008; accepted 26 January 2009. Corresponding Editor: J. F. Bruno.

${ }^{1}$ E-mail: MengeB@oregonstate.edu

${ }^{2}$ Present address: Department of Biology, Sonoma State University, Rohnert Park, California 94928 USA.

${ }^{3}$ Present address: School of Earth and Atmospheric Sciences, Georgia Institute of Technology, Atlanta, Georgia 30332-0340 USA. coastal regions that are driven by apparent alterations in coupled ocean-atmosphere forcings and not by nutrient runoff from land (e.g., Grantham et al. 2004, Chan et al. 2008, Shaffer et al. 2009). The ultimate drivers of such climatic shifts are not yet understood, nor are the ecosystem consequences, and identifying these and related phenomena warrants sharply focused scrutiny.

This example highlights a major problem facing coastal ecologists: our knowledge of the dynamics of coastal ecosystems remains limited, especially at the spatial and temporal scales necessary to understand responses to climate change. Lengthy ecological time series data sets are required to gain a temporal perspective on contemporary patterns and their trends (Parmesan and Yohe 2003), but such data sets are limited, especially in marine ecosystems (Duarte et al. 1992, Richardson and Poloczanska 2008). Long-term and large-scale data sets on ecological dynamics and associated physical and meteorological changes are sorely needed.

Propagule (larvae, spores, seeds) inputs can be a key factor in determining community structure (Underwood and Denley 1984, Menge and Sutherland 1987, Denny and Paine 1998, Connolly and Roughgarden 1999, 


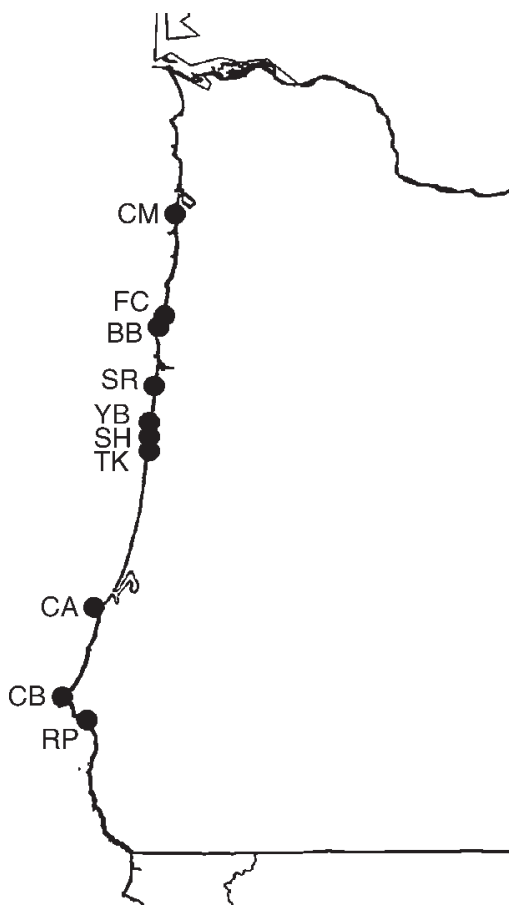

FIG. 1. Location of study sites ranging over $320 \mathrm{~km}$ along the Oregon, USA, coast. From the north, the sites are Cape Meares (CM; 45 $\left.34^{\prime} 12^{\prime \prime} \mathrm{N}, 123^{\circ} 58^{\prime} 12^{\prime \prime} \mathrm{W}\right)$, Fogarty Creek (FC; $\left.44^{\circ} 50^{\prime} 24^{\prime \prime} \mathrm{N}, 124^{\circ} 3^{\prime} 36^{\prime \prime} \mathrm{W}\right)$, Boiler Bay (BB; $44^{\circ} 49^{\prime} 48^{\prime \prime} \mathrm{N}$, $124^{\circ} 3^{\prime} 36^{\prime \prime} \mathrm{W}$ ), Seal Rock (SR; $44^{\circ} 30^{\prime} \mathrm{N}, 124^{\circ} 5^{\prime} 24^{\prime \prime} \mathrm{W}$ ), Yachats

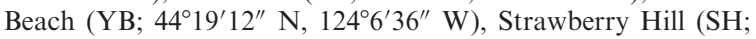
$44^{\circ} 15^{\prime} \mathrm{N}, 124^{\circ} 7^{\prime} 12^{\prime \prime} \mathrm{W}$ ), Tokatee Klootchman (TK; $44^{\circ} 12^{\prime} \mathrm{N}$, $124^{\circ} 7^{\prime} 12^{\prime \prime} \mathrm{W}$ ), Cape Arago (CA; 43⒈ $18^{\prime} 36^{\prime \prime} \mathrm{N}, 124^{\circ} 24^{\prime} \mathrm{W}$ ), Cape Blanco (CB; 42 $50^{\prime} 24^{\prime \prime} \mathrm{N}, 124^{\circ} 34^{\prime} 12^{\prime \prime} \mathrm{W}$ ), and Rocky Point (RP; $\left.42^{\circ} 43^{\prime} 12^{\prime \prime} \mathrm{N}, 124^{\circ} 28^{\prime} 12^{\prime \prime} \mathrm{W}\right)$.

Sagarin et al. 1999, Menge et al. 2003, Foster and Dickson 2004, Paine and Trimble 2004, Smith et al. 2006, Britton-Simmons and Abbott 2008, Chan et al. 2008). For example, while the influence of high rates of recruitment on population abundance is often modified by post-recruitment processes such as species interactions and environmental stress, low recruitment rates can be an important, limiting determinant of adult abundances (Connell 1985, Gaines and Roughgarden 1985, Minchinton and Scheibling 1991, Menge 2000). Because of these contrasting influences, ecologists increasingly have focused on quantifying the dynamics of propagule transport and input to ecosystems (e.g., Connolly et al. 2001, Menge et al. 2004, O'Riordan et al. 2004, Navarrete et al. 2005, Shanks and Brink 2005, Broitman et al. 2008). The important role of recruitment in community dynamics, its tight linkage to oceanographic forcing, and the advent of impacts of climate change on ecosystem functioning lends urgency to the need to better understand the coupling between propagule inputs, population and community consequences, and the alteration of these linkages as climate changes (e.g., Harley et al. 2006, Parmesan 2006).
Although some climatic patterns, such as the El NiñoSouthern Oscillation (ENSO) vary on relatively short timescales (3-7 years), others such as the Pacific Decadal Oscillation (PDO; 20-30 years) and the recently identified North Pacific Gyre Oscillation (NPGO; 10 years; see Di Lorenzo et al. 2008) last much longer. Most long-term ecological data sets are far shorter than several cycles of the longer climate patterns, and thus our ability to resolve ecosystem impacts of these longer climate changes in relation to cycle periodicity is very limited. Nonetheless, examining the relationships between ecological rates or processes and dominant climatic cycles, even for shorter than optimum time series, may offer insight into the potential for climate change to impact key ecological processes in open marine communities (Menge et al. 2008). Using data sets ranging in length from 14 to 18 years, we investigated the possible factors underlying dramatic shifts in the recruitment of mussels along the Oregon coast. We ask four questions: (1) What are the long-term patterns of recruitment of mussels, Mytilus spp., and abundance of phytoplankton along the Oregon coast? (2) How have these patterns changed? (3) What is the relationship between phytoplankton abundance, a primary food source for mussel larvae, and mussel recruitment? (4) How are phytoplankton abundance and mussel recruitment related to ENSO, PDO, and NPGO climate cycles?

We show that mussel recruitment increased dramatically in the 2000s compared to the 1990s, that recruitment was positively related to phytoplankton abundance during this time, that seasonal peak abundances of these components shifted in opposite directions, and that variation in phytoplankton and recruitment were most strongly associated with variation in NPGO, and showed weaker associations with ENSO (using the multivariate El Niño-Southern Oscillation Index or MEI) and PDO indices during this time period.

\section{Methods}

\section{Study sites}

In 1989, monthly sampling of mussel recruitment was initiated at two sites, Boiler Bay and Strawberry Hill (Fig. 1). To increase the spatial resolution and geographic range of these studies, we added sites in 1994 (Fogarty Creek, Seal Rock), 1995 (Cape Meares, Cape Arago), 1997 (Yachats Beach), 1999 (Tokatee Klootchman), and 2000 (Cape Blanco, Rocky Point). Phytoplankton sampling commenced in 1993 at Boiler Bay and Strawberry Hill, and other sites were added in 1994 (Cape Meares, Fogarty Creek, Seal Rock, Cape Arago, Cape Blanco), 1998 (Yachats Beach), 1999 (Tokatee Klootchman), and 2003 (Rocky Point). Thus the longest time series was 18 years for recruitment and 14 years for phytoplankton.

\section{Recruitment}

Quantification of recruitment employed plastic mesh ovoids ("tuffies"; SOS, The Clorox Company, Oakland, 
California, USA; Menge et al. 2004). The mesh of these collectors mimics natural mussel settlement substratum, primarily filamentous algae and the byssal threads of adult mussels (Paine 1971, 1974). Tuffies have been used in many locations around the world to quantify mussel recruitment (e.g., Leonard et al. 1998, Menge et al. 1999, Broitman et al. 2005, Navarrete et al. 2005, Porri et al. 2006), and provide a uniform substratum that allows direct comparison of recruit densities regardless of where the sample was taken.

Five to eight replicate collectors were fastened to midintertidal surfaces with lag screws inserted into wall anchors in holes drilled into the rock. At all sites, we placed the collector array on wave-exposed portions of the shore. Between-collector distances ranged from $\sim 3$ $\mathrm{m}$ to $20 \mathrm{~m}$. Collectors were usually replaced monthly, although changes in tidal pattern or winter storms sometimes shortened or lengthened the retrieval period. In the laboratory, mussel larvae were washed loose by spraying with water or were loosened using brief exposure to a dilute bleach solution, collected in sizesorting sieves, and counted under a microscope.

Connell (1985) defined recruitment as the number of competent individuals surviving for several days up to a month. Recruitment is distinct from settlement, defined as the number of planktonic individuals attaching to the substratum over a period of up to two days. Mussels $>250 \mu \mathrm{m}$ are competent to settle and are here defined as "recruits." Mussel juveniles are well known to be able to detach and reattach, a process known as secondary settlement (Bayne 1964). Our method does not allow distinguishing between primary and secondary settlers, but by restricting our counts to individuals between 250 and $350 \mu \mathrm{m}$, we infer that our samples consisted mostly of individuals in their first settlement spot. Recruitment densities were standardized to the number of mussel recruits per tuffy $\left(\sim 100 \mathrm{~cm}^{3}\right)$ per day.

Since our sampling program was designed to provide insight into the number of propagules available to adult populations at larger spatial scales (multiple sites over kilometers to hundreds of kilometers) and longer (years) timescales and how this varied in space and time, timecost trade-offs dictated a relatively low-frequency (monthly) sampling approach (e.g., Broitman et al. 2008). Consequently our monthly estimates of recruitment are influenced by both settlement and postsettlement factors such as mortality from physical or biological sources. We realize that comparisons could be compromised if post-settlement factors impose density dependent mortality on recruit numbers. Evaluation of this issue (Broitman et al. 2008) suggests that postsettlement mortality is primarily density independent. For example, comparing average monthly recruit densities to the maximum density ever observed indicates that only $1.14 \%$ of the possible maximum mussel recruitment density is reached, suggesting density-dependent effects from other mussel recruits is unlikely. Further, for barnacles, the relationship between recruit density and density of settlers (cyprids) found on monthly plates (i.e., those larvae that have settled within the past 24 hours) is always positive (Broitman et al. 2008; B. A. Menge and M. Foley, unpublished manuscript). Limited data are available for mussels, but here too, regressions between recruits and settlers appear positive (Rilov et al. 2008).

Caveats.-Because of trade-offs inherent in different sampling frequencies and intensities, our sampling frequency does not allow the evaluation of mechanisms of larval transport. That is, monthly estimates of recruitment cannot resolve the effects of processes such as tidal bores, internal waves, current reversals and other processes that operate on scales of hours to days to weeks and are presumably the physical means by which larvae are delivered to the shore (e.g., Pineda 1999, Shanks and Brink 2005, Pineda et al. 2007). Assessing the importance of these processes in determining larval transport and settlement requires highfrequency sampling scaled to match their temporal patterns of variability (e.g., Tapia et al. 2004). Highfrequency sampling is time consuming and costly, however, so available resources typically limit spatial and temporal scopes to one or few sites and relatively short time spans. However, monthly sampling is sufficient to determine the cumulative effect of the suite of oceanographically mediated transport mechanisms that determine the apparent rate of mussel recruitment at a given site during that period.

Although morphological characteristics have been used by some workers to distinguish between Mytilus trossulus and M. californianus juveniles (Martel et al. 1999), in our experience using such methods to distinguish between the larvae of mussel species has been unreliable. Our samples have also included the occasional individual of Modiolus sp. (an estuarine species), but these easily can be distinguished morphologically from Mytilus and are scarce. Our analyses thus examined how pooled numbers of mussel (= Mytilus spp.) recruits responded to the different factors examined. This raises the possibility that patterns observed are confounded by inclusion of different mussel species that may vary differently in response to various environmental factors. Judging from the species composition of the juvenile mussels that appear on the shore in winter (a few months after the heaviest settlement pulses; Menge et al. 1994, Navarrete and Menge 1996, Navarrete et al. 2000), most recruits are M. trossulus.

Comparison of monthly samples to monthly estimates of climate and upwelling indices assumes that recruitment reflects the net effects of variation in sea-surface temperature (the basis of ENSO and PDO indices; Wolter 1987, Francis et al. 1998) and ocean circulation (the basis of NPGO; Di Lorenzo et al. 2008). While variation in these measures can be estimated on a daily basis, and variation in phytoplankton and recruitment can clearly occur on daily timescales, analyses presented elsewhere (Broitman et al. 2008) indicate that evaluation 
at monthly scales is a robust reflection of climatic variation.

\section{Phytoplankton}

We quantified the concentration of chlorophyll $a$ (hereafter termed chl $a$ ), a proxy for phytoplankton abundance, in bottle samples taken from shore at each site (Menge et al. 1997, Leslie et al. 2005, Barth et al. 2007). Samples were taken daily to monthly during the April-October upwelling season. Annual and monthly mean chl $a$ by site was calculated as the average of the sample means during the upwelling season. As noted previously (Menge et al. 2008), chl $a$ was on average low in winter $(2.5 \pm 0.3 \mathrm{mg} / \mathrm{L} ; n=29)$ compared to summer $(14.3 \pm 0.9 \mathrm{mg} / \mathrm{L} ; n=379)$. In contrast to summer sampling, winter sampling was sparse and uneven among sites, so it seemed reasonable to limit comparisons to upwelling season estimates.

At low tide, replicate $(n=3-5)$ acid-washed opaque plastic 250-mL bottles (HDP; high density polyethylene) were filled at a depth of $30-50 \mathrm{~cm}$ below the surface. Fifty milliliters of water were immediately filtered in the field through 25-mm pre-combusted Whatman $\mathrm{GF} / \mathrm{F}$ glass-fiber filters with a pore size of $0.7 \mu \mathrm{m}$. Filters were stored on ice and returned to the laboratory where chl $a$ concentration was determined using a Turner Designs TD-700 fluorometer (Turner Designs, Sunnyvale, California, USA) after extraction in $90 \%$ HPLC acetone for $12 \mathrm{~h}$ in the dark at $-20^{\circ} \mathrm{C}$. Prior calibrations of the fluorometer were done using pure chl $a$ standards.

\section{Climatic patterns}

In our analyses we compared monthly measures of mussel recruitment and chl $a$ concentration to monthly values of indices for ENSO (using the MEI index), PDO and NPGO. Data for the MEI, PDO, and NPGO were downloaded from web sites. ${ }^{4,5,6}$ By convention, values of the MEI and PDO indices $>0$ indicate warm water conditions $(\mathrm{El}$ Niño $=\mathrm{MEI}>+0.5)$ and indices $<0$ indicate cool water conditions (La Niña $=\mathrm{MEI}<-0.05$ ). The newly identified NPGO is based on analysis of seasurface temperature anomalies and sea-surface height anomalies, and according to Di Lorenzo et al. (2008) "reflects changes in wind forcing and the intensity of North Pacific gyre-scale circulation."

\section{Tide height}

At each site, mussel recruit collectors were placed in the vertical center of the mussel bed in positions that remained fixed through time. However, mussel bed height can vary among sites (Menge et al. 1994). To determine if among-site variability in the height at which collectors were deployed contributed to recruitment variation, we measured the height above mean lower low

\footnotetext{
${ }^{4}\langle$ http://cdc.noaa.gov/ENSO/enso.mei_index $\rangle$

${ }^{5}\langle\mathrm{http}: / /$ jisao.washington.edu/pdo/>

${ }^{6}\langle\mathrm{http}: / /$ www.ocean3d.org/npgo $\rangle$
}

water (MLLW) of each collector at each site using surveying methods (Menge et al. 2008). The positions of collectors were fixed so we took height measurements once, in July 2007.

\section{Sea level}

To test the possibility that mussel recruitment varied with changes in sea level, we obtained monthly sea level data for South Beach, Oregon $\left(44^{\circ} 22^{\prime} 48^{\prime \prime}\right.$ N, 124 $4^{\prime} 1^{\prime} 48^{\prime \prime}$ W) from the Joint Archive for Sea Level (JASL; data available online). ${ }^{7}$ South Beach is centrally located among our study sites with the longest time series (Fig. 1; in order from north, FC, BB, South Beach, SR, and $\mathrm{SH}$ ). Since the nearest sea level stations to the north (Tillamook, Oregon) or south (Charleston, Oregon) were quite distant from these four core sites with the longest time series, we assumed that sea level measures obtained for South Beach applied to all four sites.

\section{Data analysis}

Ideally, because of the likelihood of temporal autocorrelation in some of our data sets, time series analysis approaches would be employed. In fact, preliminary analysis suggested that for mussel recruitment, significant autocorrelation exists between samples taken within three-month windows. However, the recruitment data are not continuous, with occasional data gaps ranging from one to three months, and thus violate the requirement of regularity in sampling intervals for time series analysis (Chatfield 2004). Further, the phytoplankton data were taken at very irregular time intervals with most sampling occurring in the upwelling season and little in fall or winter. For these reasons, we primarily used analysis of variance and regression approaches in data analysis. Because of the potential confounding due to autocorrelation in some data sets, we interpret our analyses cautiously.

Data were analyzed using JMP 7.0 (SAS Institute 2007). Two-way analysis of variance (ANOVA) tested the effect of month and decade on monthly recruitment of mussels and on chl $a$ at each site. Data were normalized prior to analysis using log-transformations $(\ln [x+1])$. Levene's test evaluated the assumption of homogeneity of variances; in cases where the assumption was violated, we used Welch ANOVA tests (allows unequal variances) to check for consistency with the results of two-way ANOVA tests on main effects (see Appendix A). In all relevant cases, the violation of the assumption of equal variances did not influence results. In all cases, we examined residuals visually to evaluate the assumption of normality. Leverage plots were inspected to identify outliers. We used linear regression to examine the relationships between phytoplankton abundance or mussel recruitment and each climate index. We used multiple regression to test the dependence of mussel recruitment on phytoplankton abun-

\footnotetext{
${ }^{7}\langle$ http://uhslc.soest.hawaii.edu/uhslc/jasl $\rangle$
} 
dance and the NPGO. Because of multicollinearity among the different indices (data not shown), we do not present multivariate analyses examining relationships among phytoplankton abundance or mussel recruitment and the climate indices combined.

Phytoplankton typically respond to nutrient pulses within three days, so our regression analyses of chl $a$ assumed no lag between the climate index and the chl $a$ value: means of chl a samples were regressed against mean indices for the same month. In contrast, since larval durations are two to four weeks (Strathmann 1987), we incorporated a one-month lag in recruitment analyses: monthly mean recruitment data were regressed against index values from the previous month.

\section{RESULTS}

\section{Mussel recruitment}

Inter-decadal change.-Several patterns are evident in the mussel recruitment time series across the ten study sites (Fig. 2). Most obviously, in 2000 mussel recruitment increased dramatically and synchronously at most sites. This pattern persisted for several years, from 2000 to 2004, and at several sites (BB, SH, TK, CA, CB) to 2005. In 2006, peak recruitment was similar to that observed prior to 2000. Comparing overall average recruitment from the first (1989-1999) to the second period (2000-2006) reveals that for sites with the longest time series, recruitment was greater in the 2000s at all but the northern- and southernmost sites (CM and CA, Fig. 3).

Mussel recruitment also varied consistently in space and time. Among-site variation in mussel recruitment, for example, was substantial, with peak densities spanning almost three orders of magnitude (Fig. 2; note scale differences on $y$-axis). These among-site differences were generally persistent through time, even through the period of the huge increase in recruitment observed in the 2000s (Fig. 3; only the ranks of CM and SR switched from 1989-1999 to 2000-2006, see also Navarrete et al. 2008). In general, mussel recruitment tended to be higher at the northern sites (Fig. 2, CM to TK) than at the southern sites (CA to RP), a trend noted earlier by Connolly et al. (2001) and Menge et al. (2004). Note also that sites in close proximity (e.g., FC and BB, $\sim 500 \mathrm{~m}$ apart) sometimes had very different recruitment rates.

Seasonal change.-At several sites, mostly those with the longer time series, a shift in seasonality of recruitment accompanied the inter-decadal shift in mussel recruitment density (Fig. 4). In the 1989-1999 decade, peak mussel recruitment tended to occur in summer, primarily July and August. After 2000, however, recruitment peaks shifted by one to three months, usually occurring in September or October, and recruitment by month became more variable (Fig. 4). As noted above for overall changes in recruitment density, the northern- and southernmost sites did not show major changes in seasonality, except for October at CM. Monthly comparisons at YB, CA (Fig. 4), TK, and CB (not shown) were all limited by either relatively few pre2000 sample month-years, or months in the 1989-1999 period for which no data were available. At YB, the higher overall recruitment in the $2000 \mathrm{~s}$ and the significant main effect of month (Fig. 3, Appendix A: Table A1) suggests that with a larger pre-2000 sample, between-month differences would have been detected.

\section{Phytoplankton}

What caused the increases in mussel recruitment and the shift in seasonality? Two possibilities are shifts in food availability and in current patterns. Mussel larvae feed on components of phytoplankton as well as detritus and bacteria (Bayne 1983, Lutz and Kennish 1992), so we examined the relationship between phytoplankton concentration and mussel recruitment.

Inter-decadal change.-As with mussel recruitment, annual patterns of upwelling season (April-September) chl $a$ varied among sites and among years (Fig. 5). Interannual variation often occurred synchronously among adjacent sites (e.g., 1997 vs. 1994-1996 for at least the four northern sites), and sometimes across all sites (e.g., 1999 vs. all other years) but interannual synchrony was less striking than occurred with mussel recruitment (Fig. 2). For five of eight sites with sufficiently long time series, chl $a$ varied by decade (two-way ANOVA, decade $\times$ site interaction, $P=0.025$; $\left.\mathrm{df}=8,1034, R^{2}=0.321\right)$. Higher chl $a$ occurred in the $2000 \mathrm{~s}$ at $\mathrm{FC}(P<0.0001), \mathrm{BB}(P<0.0001)$, YB $(P=$ $0.036)$, SH $(P<0.0001)$, and CA $(P=0.003)$, but did not differ between decades at the northernmost site CM $(P=0.19)$, at centrally located SR $(P=0.09)$ or at the southernmost site $\mathrm{CB}(P=0.94)$.

Seasonal change.-In addition to the inter-decadal increase in phytoplankton concentration, analysis of changes by month in the upwelling season (AprilSeptember) suggests that phytoplankton blooms shifted in season, occurring about a month earlier in the season at several sites including $\mathrm{FC}, \mathrm{YB}$, and $\mathrm{SH}$ (Fig. 6; Appendix A: Table A2, month effect or month $\times$ decade effect). Linear contrasts (Fig. 6, Appendix A: Table A2) suggest that at $\mathrm{FC}, \mathrm{YB}, \mathrm{SH}, \mathrm{CA}$, and perhaps $\mathrm{SR}$ the peak was typically in August in 1993-1999 and in July in 2000-2007. No obvious change in seasonality was observed at CM, BB, or CB.

Association between food concentration and recruitment.-Analyzing combined data from the four sites with the longest time series (FC, BB, SR, SH) reveals that mussel recruitment increases with increasing phytoplankton concentration (Fig. 7; $P<0.0001, R^{2}=$ $0.16)$. This suggests that the higher food concentration that occurred at these sites in the 2000s could be at least partly responsible for the increases in recruitment. However, this inference simply alters the question to what factor(s) are responsible for the shifts in phytoplankton concentration? Both nutrient inputs and transport processes are likely explanatory variables correlated with the climatic indices we are examining, 


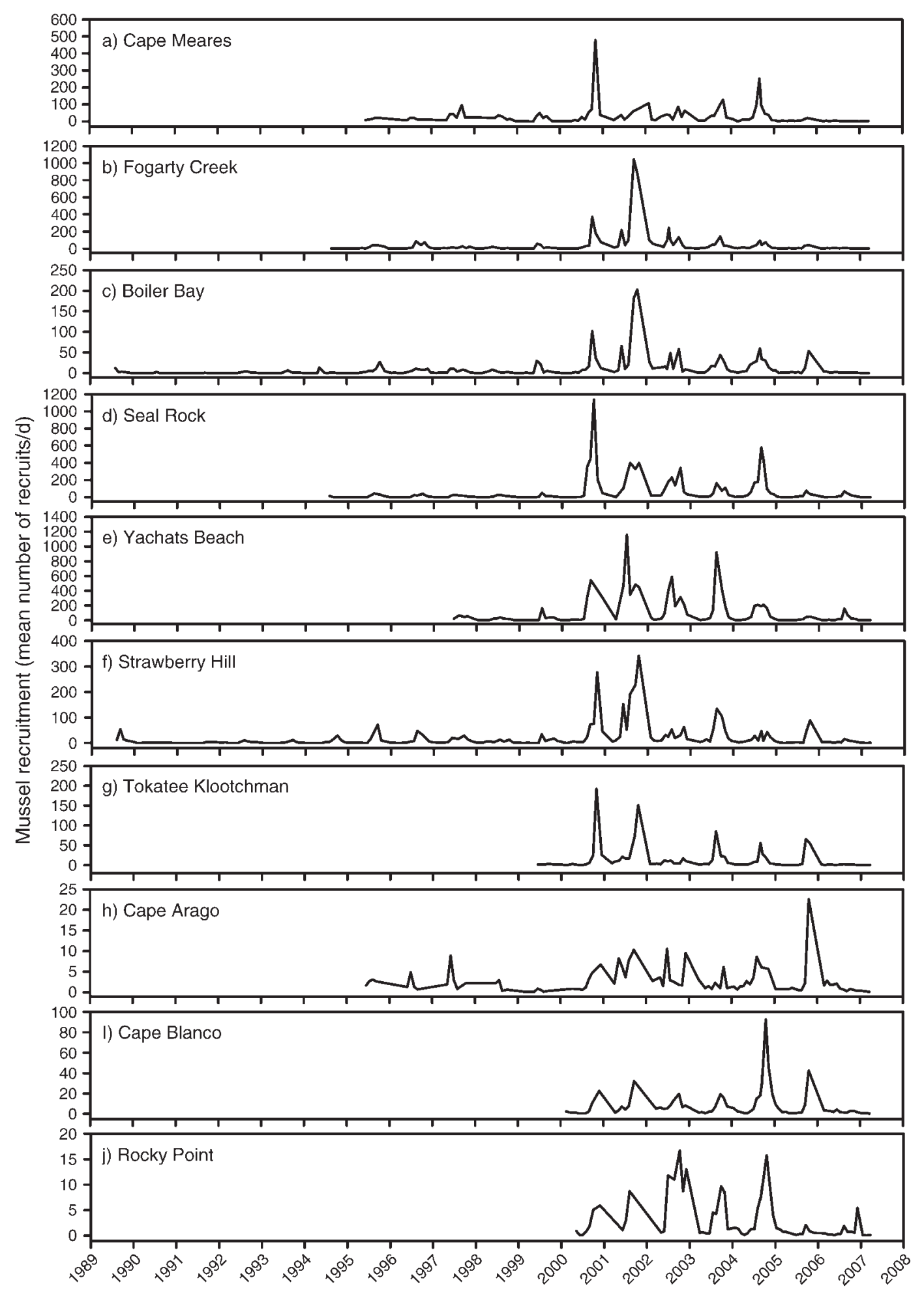

FIG. 2. Time series of mussel recruitment (monthly mean number of recruits per day; error bars not shown for clarity) at 10 sites along the Oregon coast (see map in Fig. 1). Note that $y$-axis scales differ among sites. 
FIG. 3. Mussel recruits per day (mean + SE) in 1989-1999 vs. 2000-2006 at seven sites along the Oregon coast (see map in Fig. 1). Two-way ANOVA on $\ln ([$ mussel recruits/d] +1$)$ indicated that recruitment varied by site and period (site $\times$ period interaction, $P=0.004$ ). Results of linear contrasts are indicated by asterisks. In 2000-2006 recruitment was higher than recruitment in 19891999 at FC, BB, SR, YB, and SH. Numbers above bars indicate rank orders in the two periods.

** $P \leq 0.01 ; * * * P \leq 0.001 ;$ ns, not significant.

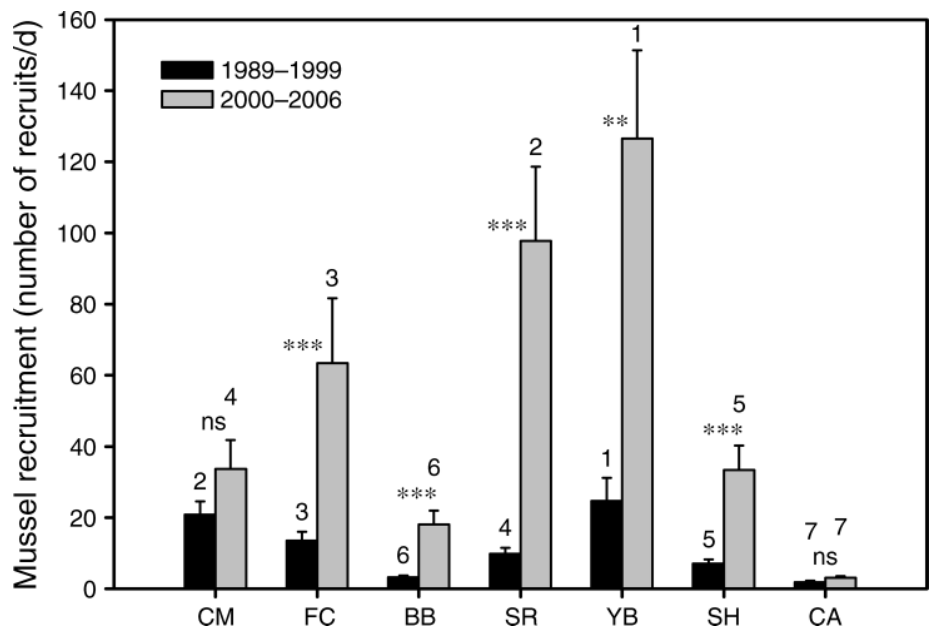

and disentangling these two processes is not possible given the data available since other processes such as changes in currents or sea level might also contribute to the change in mussel recruitment. For example, the large amount of variation not explained by chl $a$ concentration in Fig. $7(\sim 84 \%)$ seems a clear indication that other factors are involved. The asynchrony in the interdecadal shift between seasonal patterns of phytoplankton (earlier at more than half the sites, from August to July) and mussel recruitment (later at most sites, from July-August to September-October) also suggests that despite the positive relationship in Fig. 7, factors other than simple trophic linkages may underlie aspects of the observed shifts. Finally, the among-site variation in these responses suggests that local- to mesoscale variability in space is also likely to influence the pattern of inter-decadal change. Thus, the observed patterns suggest that both large-scale and smaller-scale processes may have influenced long-term patterns of recruitment. Below we address the possible influences of climate patterns, sea level and variation in the height of deployment of collectors on the shore.

\section{Climatic factors}

From 1989-2007, all three of the climate patterns fluctuated between the extremes of each type of cycle (Fig. 8). For example, the 1990s saw several El Niños, including the most intense in recorded history (19971998) and two strong La Niñas $(1989,1999)$, while in the 2000s, two to three weak El Niños (2003, 2004-2005, 2007) and two La Niñas (2001, 2008) occurred. The PDO varied substantially over the 1989-2007 period but showed more warm periods in the 1990s and more cool periods in the 2000s (Fig. 8) including the 1998-2003 period that seemed to signal the long-anticipated shift from the warm phase that began in 1977 (Peterson and Schwing 2003). The NPGO cycled more consistently but there were still periods of stronger and weaker gyre-scale circulation in both the 1990s and 2000s, specifically in the strength of the North Pacific Current (NPC) (Fig. 8).
Univariate analyses.-Analysis indicates that the NPGO cycle had the strongest association with phytoplankton concentration (Fig. 9c; $P<0.0001, R^{2}=$ $0.103)$. Periods of stronger NPC $($ NPGO $>0)$ had higher chl $a$ concentrations (Fig. 9c). Although the regression between PDO and chl $a$ was significant, only $3.8 \%$ of the variance in phytoplankton abundance was explained (Fig. 9b), and ENSO explained a trivial amount of variance $(0.3 \%$; Fig. $9 \mathrm{a})$. Chl $a$ concentration evidently tends to be lower under conditions of warmer water and weaker winds (PDO >0; Fig. 9b).

Similar trends were seen for the relationship between mussel recruitment and the climate indices. The NPGO cycle had the strongest effect on mussel recruitment, explaining $13 \%$ of the variance (compared to only $2 \%$ for PDO and $0.2 \%$ for ENSO; Fig. $10 \mathrm{a}-\mathrm{c}$ ). Trends in recruitment-climate-index relationships were also similar to those of phytoplankton. Recruitment was higher with stronger NPC (Fig. 10c), lower with warmer water (Fig. 10b) and was unaffected by ENSO.

More detailed analyses, by site and/or season, reveal interesting complexities to these overall patterns. First, the signal of NPGO is strong across all four sites, both for chl $a$ and recruitment, although the variance explained differs among sites (3-17.4\% for chl $a$, 6$16 \%$ for recruitment; see Appendix A: Table A3 and Fig. 11a for mussels vs. NPGO). The substantial level of unexplained variation is not surprising, given the high month to month variation in chl $a$ and mussel recruitment and the huge differences in spatial scale over which the NPGO index and the chl $a$ and recruitment data were quantified. To explore further whether smoothing the data improved the fit, however, we low-pass filtered the NPGO and recruitment data. This changed the correlations only marginally, however, so we chose to present the results based on the original time resolution (Fig. 11a). The source of the unexplained variation remains unclear, and may require longer time series to resolve. 

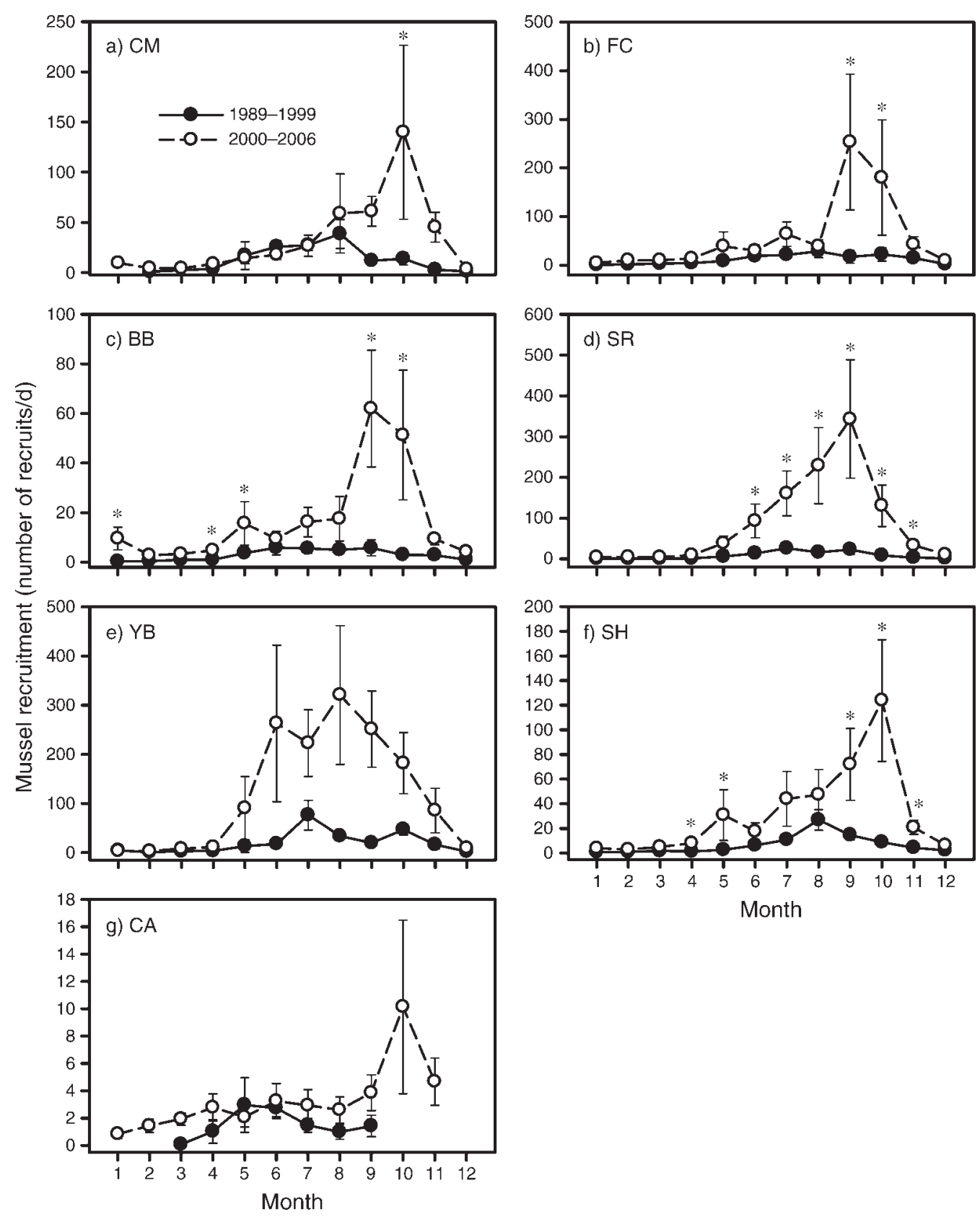

FIG. 4. Seasonal patterns of mussel recruitment (mean \pm SE) in 1989-1999 vs. 2000-2006 (month $1=$ January, $2=$ February, and so on). Asterisks indicate months in which the inter-decadal difference was significant $(P<0.05)$ based on linear contrasts in a two-way ANOVA (month, decade). No differences were significant at YB and CA.

In contrast to the consistent correlations between NPGO and chl $a$ or mussel recruitment, signal strength of PDO and ENSO varies in space. For chl $a$ and recruitment, PDO effects occurred at FC, SR, and $\mathrm{SH}$ (chl $a$ ), and at SR only (recruitment), but not at other sites. Similarly, ENSO effects occurred at FC and SR (chl $a$ ) and BB (recruitment) but not elsewhere. Second, responses also varied by season with index. Assuming traditional seasons, NPGO effects were strong in all seasons (recruitment) or all seasons but winter (chl $a$ ).
PDO effects occurred in spring and summer ( $\operatorname{chl} a)$ and summer and fall (recruitment), and ENSO effects occurred in spring and summer (chl a) and summer and fall (recruitment; Appendix A: Table A3).

\section{Multivariate analyses}

Consistent with the univariate analyses showing increases in mussel recruitment with phytoplankton (Fig. 7) and NPGO (Fig. 10c) and increasing phytoplankton with NPGO (Fig. 9c), mussel recruitment 

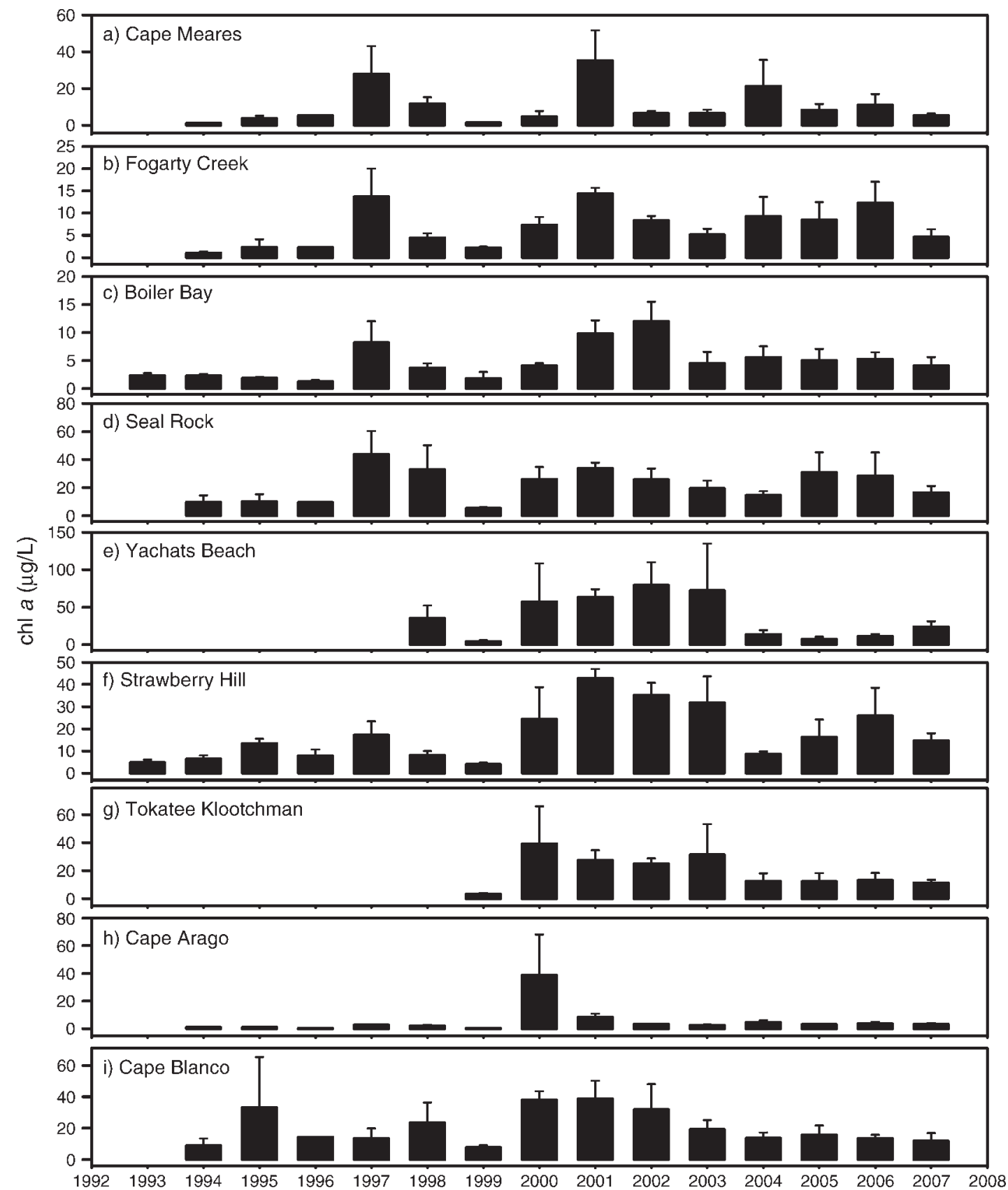

FIG. 5. Annual upwelling season (April-September) chlorophyll $a(\operatorname{chl} a$; mean $+\mathrm{SE})$ time series at nine sites along the Oregon coast, 1993-2007.

increased with both increasing phytoplankton abundance and stronger basin-scale winds and currents (positive NPGO; Fig. 12). The multiple regression was substantially stronger than the univariate regressions, explaining $50 \%$ of the variance vs. $10-16 \%$ for the univariate analyses.

\section{Tide height}

The height on the shore of collectors varied among sites, occurring higher at TK $(+2.1 \mathrm{~m})$ and lower at BB
$(+1.7 \mathrm{~m})$ and $\mathrm{YB}(+1.25 \mathrm{~m})$ than at the other six sites (Appendix B: Fig. B1). Despite this variation, mussel recruitment did not vary with collector height on the shore at least over this range of heights. We calculated the long-term average mussel recruitment from 2001 to 2006 (the years that the positions of replicate collectors were recorded) and regressed it against height on the shore $(\mathrm{m})$ for each replicate. Mussel recruitment density did not vary with height on the shore $(P=0.57, n=60)$, 

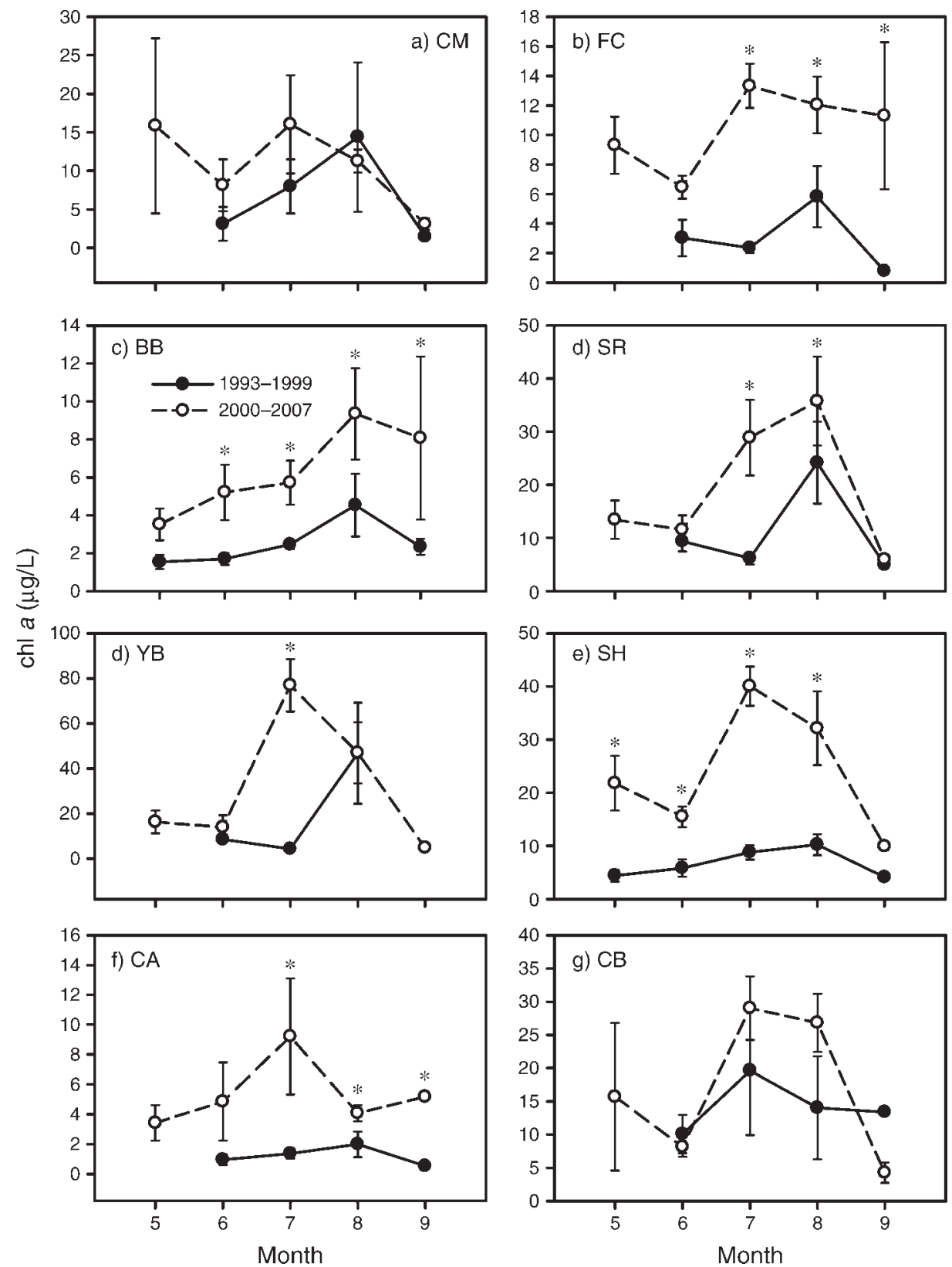

FIG. 6. Inter-decadal patterns of chl $a$ concentration by month of the upwelling season, 1993-2007. Asterisks indicate months in which chl $a$ concentrations differed between decades at $\alpha=0.05$.

suggesting that the variation in collector height on the shore was unimportant.

\section{Sea level}

In apparent contrast to results for tide heights, higher mean sea levels were associated with lower recruitment densities (Appendix B: Fig. B2; $F_{1,171}=31.7, P<0.0001$, $\left.R^{2}=0.151\right)$. This effect seems at least partly due to seasonal variation in sea level, however. During "winter" (October-March), the prevailing southerly storm pattern should raise sea level compared to summer when intermittent upwelling should lower sea level. Deletion of winter values considerably weakens the relationship $\left(F_{1,90}=5.2, P=0.025\right)$, with sea level explaining only $4.4 \%$ of the variance in recruitment. The relationship disappears if analysis is confined to May-August, the period of strongest and most persistent upwelling $\left(F_{1,60}=\right.$ 2.33, $\left.P=0.13, R^{2}=0.02\right)$. Thus, the pattern appears driven by higher sea level in winter, a period when mussel recruitment is also lowest regardless of year. We conclude that variation in sea level of this magnitude has little influence on mussel recruitment density. 


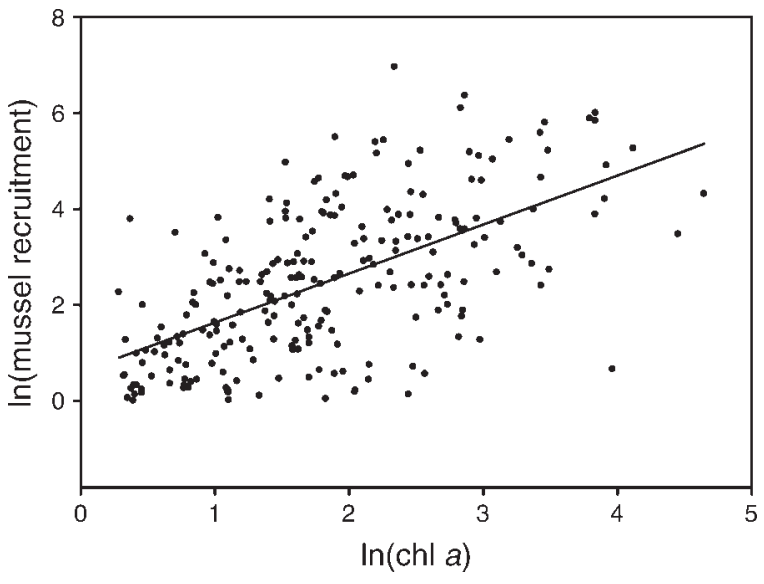

FIG. 7. Relationship between mussel recruitment per day and chl $a$ concentration across the four sites with the longest time series of recruitment and chl $a(\mathrm{FC}, \mathrm{BB}, \mathrm{SR}$, and $\mathrm{SH})$. Linear regression equation: $\ln ($ no. recruits $/ \mathrm{d})=1.122+$ $0.651(\ln [\mathrm{chl} a]) ; F_{1,319}=59.73, P<0.0001, R^{2}=0.155$.

\section{Discussion}

Mussel recruitment and phytoplankton abundance responded similarly to climate fluctuations as expressed in NPGO, ENSO, and PDO indices. Among these, the tightest relationship was with the NPGO (Fig. 11a), with ENSO and PDO having much weaker associations. Although the recruitment data set overlaps with only about one to one and a half full cycles of the NPGO, the tracking of this basin-scale climate pattern (Fig. 11a) by mussel recruitment at all four of the sites with the longest data sets is remarkable and contrasts to the poor association between PDO and mussel recruitment. This result is surprising given that in this region the PDO is well correlated with low-frequency upwelling variability (Chhak and Di Lorenzo 2007). Therefore, the lack of correlation of mussel recruitment with the PDO and the stronger correlation with the NPGO suggests that changes in the large-scale gyre circulation, rather than in upwelling winds, can strongly influence coastal ecosystem processes such as mussel recruitment. Indeed, the difference map of satellite SSH between the periods (1990-1999) when mussel recruitment was lower to (2000-2006), when mussel recruitment was higher reveal a clear intensification of the North Pacific Current (NPC) that is consistent with the NPGO pattern (Fig. $11 \mathrm{~b}, \mathrm{c})$.

Although the dynamics that link basin-scale changes in ocean circulation with coastal ecological processes need to be further investigated, we propose the following hypothesis: "changes in large-scale ocean advection associated with the NPC modulate the input of nutrient rich water masses into the coastal upwelling system and exert a primary control on low-frequency changes in coastal ecosystem food web structure." This hypothesis is supported by the strong correlation between the NPGO, chl $a$, and mussel recruitment (Fig. 12). It is also consistent with previous observational studies that link stronger hypoxia/anoxia conditions to periods of stronger intrusion of sub-arctic nutrient-rich waters in the coastal upwelling system (Wheeler et al. 2003, Grantham et al. 2004), which trigger high levels of surface production. Together, these results highlight the sensitivity of dynamic and heterogeneous inner-shelf marine ecosystems to basin-scale variations in climatic forcing. The correlation between climate modes and recruitment can further inform refinements in predictive models of recruitment, a notoriously difficult challenge for marine populations.

Inter-decadal changes.-Although the dramatic change in mussel recruitment in 2000 seems mostly strongly influenced by the NPGO, the abrupt change in this measure and the more variable response of phytoplankton abundance (Figs. 2 and 5) suggest that both phytoplankton and mussel recruitment responded in a complex way to several environmental signals.

First, phytoplankton variation did not respond simply to changes in large-scale thermal or current regimes, at
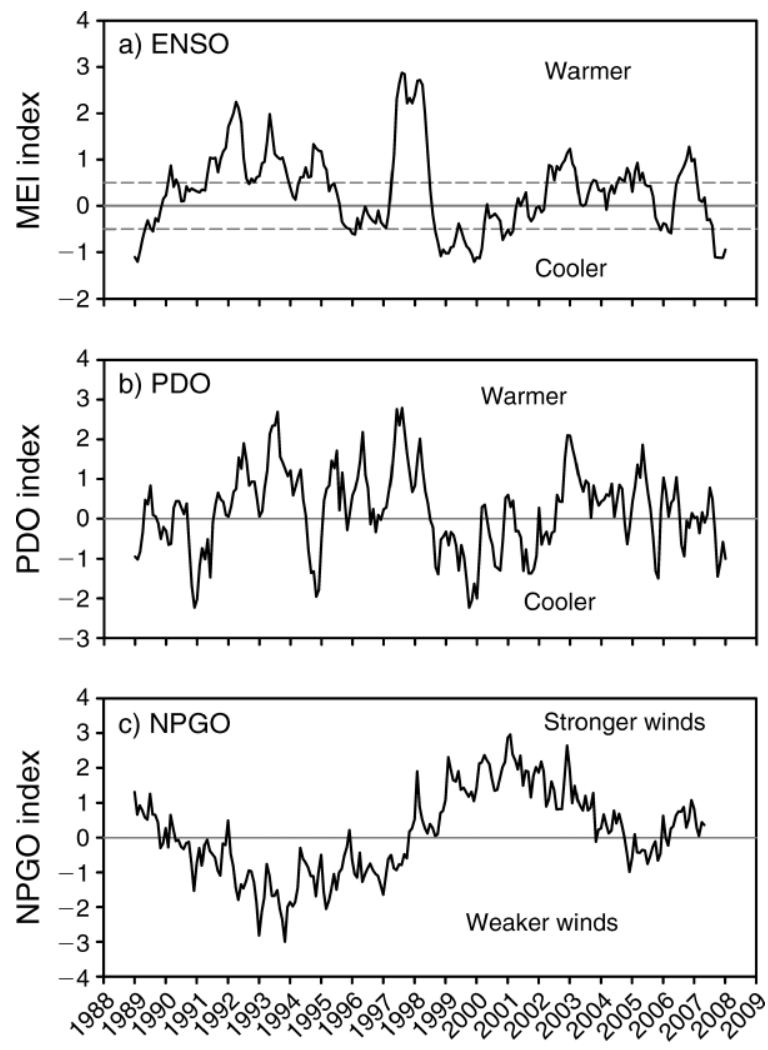

FIG. 8. Climate patterns from 1989 to 2008. In the panels, "warmer" and "cooler" and "stronger winds" and "weaker winds" refer to the physical changes associated with index values $>0$ and $<0$, respectively. Abbreviations are MEI, multivariate El Niño-Southern Oscillation index; PDO, Pacific Decadal Oscillation; NPGO, North Pacific Gyre Oscillation. In panel (a), dashed lines indicate limits of neutral ENSO index. Above 0.5 , conditions are by definition an El Niño, below -0.5 , conditions are by definition a La Niña. 

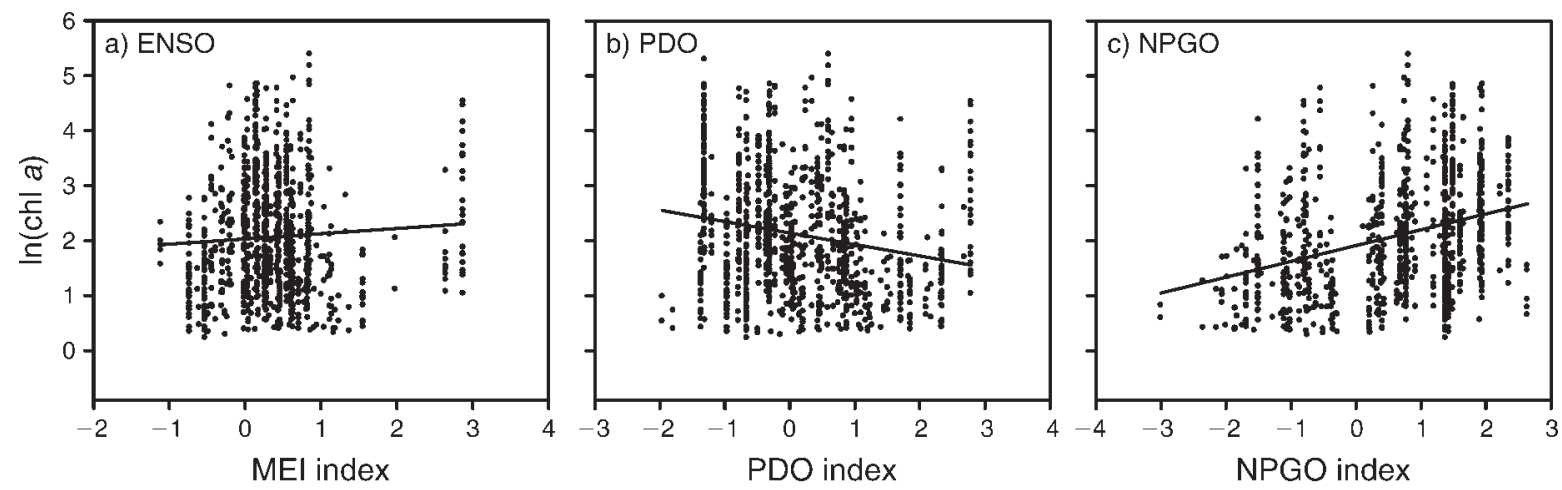

FIG. 9. Relationship between climate indices at two latitudes $\left(42^{\circ} \mathrm{N}\right.$ and $\left.45^{\circ} \mathrm{N}\right)$ and $\operatorname{chl} a($ as $\ln [\operatorname{chl} a$ concentration +1$])$. For details of analysis and sample sizes, see Appendix A: Table A2.

least not on the monthly timescales evaluated here. For example, the 1997-1998 El Niño (warm conditions) evidently spurred higher phytoplankton concentrations than usual (1997 averages were typically higher than previous years; Fig. 5), and the 1999 La Niña (cool conditions) was associated with lower phytoplankton (Fig. 5). Since warm and cool waters are typically associated with low and high nutrients, which usually spur low and high phytoplankton, respectively, the occurrence of high and low phytoplankton with warm and cool waters was unexpected. These patterns suggest that other factors, perhaps coastal currents that transport phytoplankton toward or away from shore during warm or cool water events, respectively, can trump the normal relationship between nutrients and phytoplankton. This is similar to the pattern of low chl $a$ typically associated with headlands where upwelling is often stronger and more persistent than in upwelling shadows or embayments, in the lee of headlands, or downstream from upwelling centers where phytoplankton eventually "bloom" (e.g., Wilkerson and Dugdale 1987, Graham and Largier 1997, Wieters et al. 2003).
In contrast, the higher values of phytoplankton seen during $\sim 2000-2003$ at many sites (Fig. 5) were associated with mostly neutral ENSO conditions, cool PDO conditions, and intensification of the North Pacific Current, implying southward intrusions of cool nutrientrich subarctic waters (Fig. 8). Consistent with this, water temperature records from sensors in the low intertidal recorded cooler annual average temperatures from 1999 to 2003 (Menge et al. 2008).

A striking aspect of phytoplankton patterns is how much they varied in space, along a $320-\mathrm{km}$ stretch of Oregon coastline (Fig. 5). While the trends summarized above suggest some measure of generality in space (especially the low chl $a$ values observed in $1999 \mathrm{La}$ Niña conditions), the synchrony of other changes was more limited. Taking both magnitude of chl $a$ and pattern of change into account, cluster analysis identifies approximately five site groupings (Appendix B: Fig. B3). Some of these groups include sites that are geographically close to one another with the odd site more distant (e.g., a mid-coast group that includes SR, YB, SH, and $\mathrm{TK}$, with $\mathrm{CB}$ as the geographic outlier; the northern sites
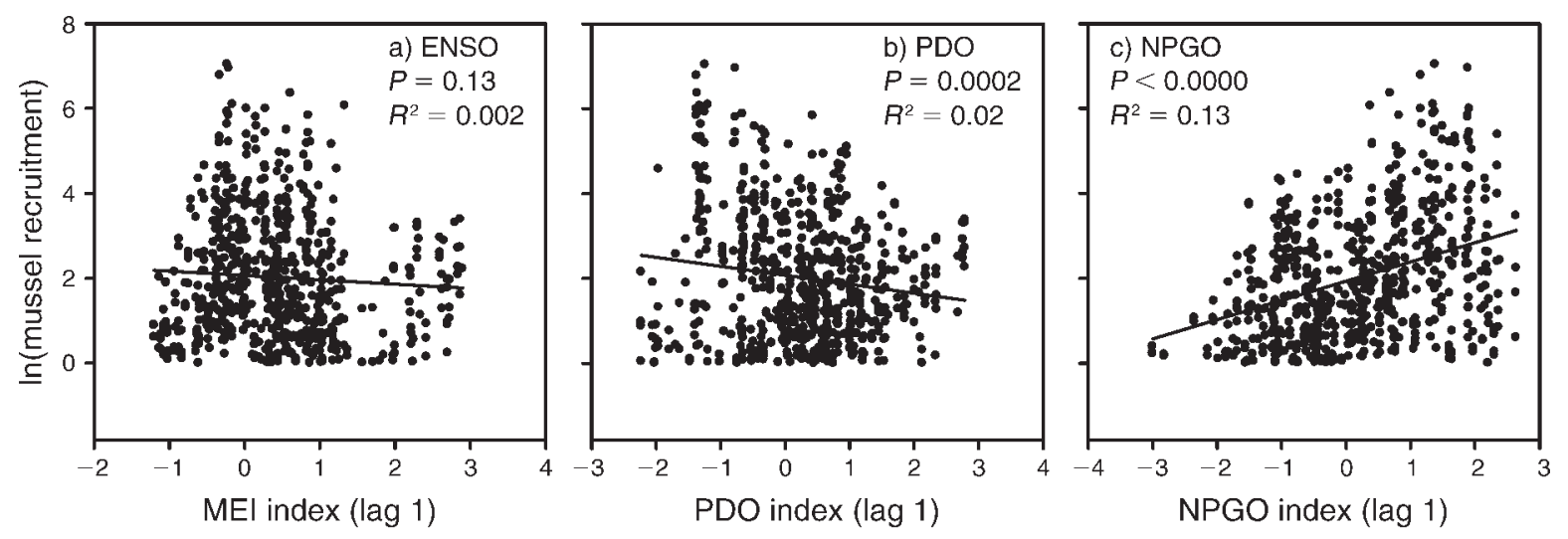

FIG. 10. Relationship between climate indices at two latitudes $\left(42^{\circ} \mathrm{N}\right.$ and $\left.45^{\circ} \mathrm{N}\right)$ and mussel recruitment (measured as no. recruits/d). Lag 1 means that the mussel recruitment data are plotted against the NPGO index for the previous month, the idea being that a recruitment response will be seen to conditions occurring when the mussel larvae were in the water column, which would be in the month leading up to the recruitment measure because larval life lasts about a month or so. For details of analysis and sample sizes, see Appendix A: Table A2. 

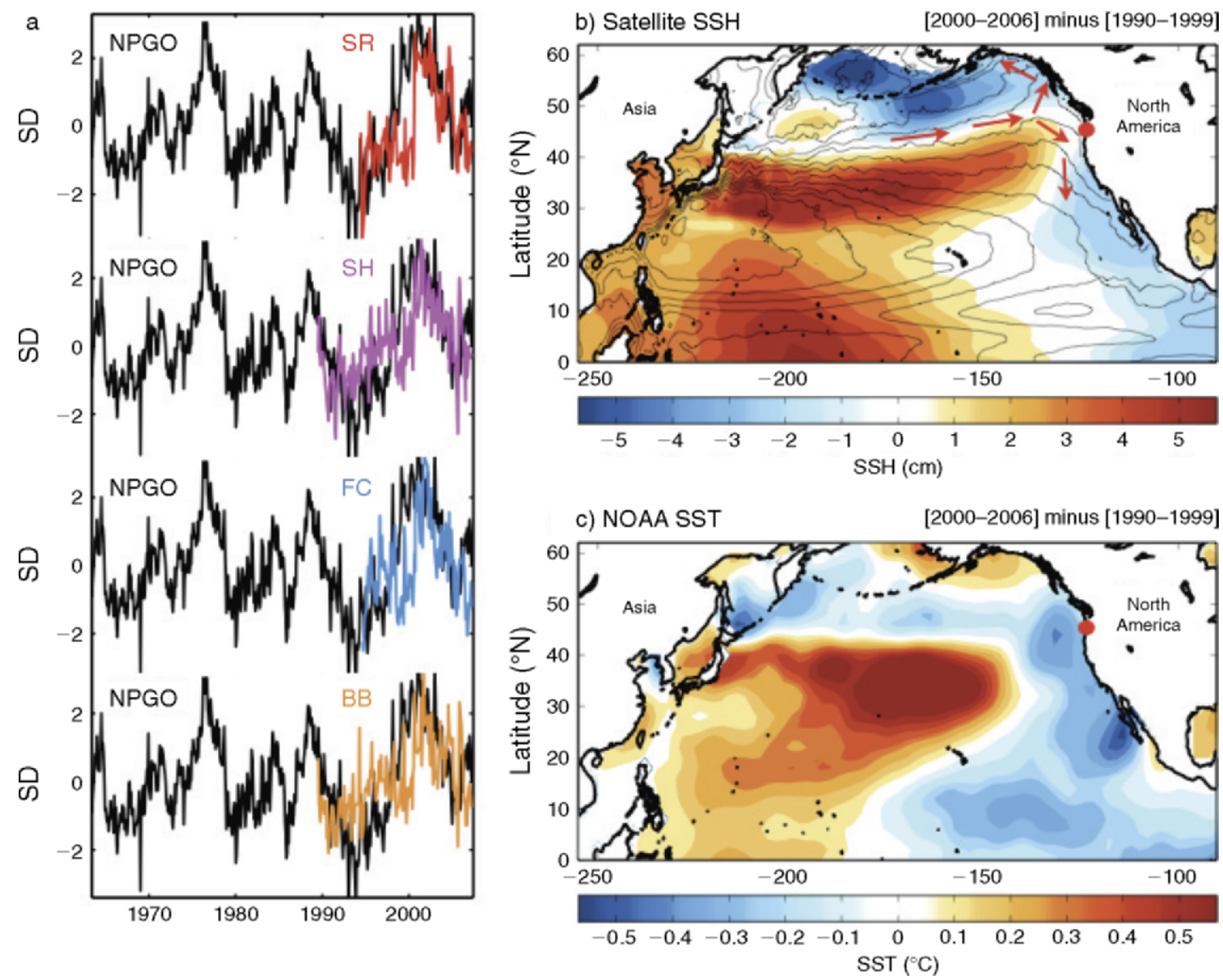

FIG. 11. (a) Time series of normalized mussel recruitment at four locations (SR, SH, FC, and BB) compared to the North Pacific Gyre Oscillation (NPGO) index. The time series are normalized by their standard deviation (SD; the $y$-axis scale numbers indicate the actual standard deviations of the NPGO index, by which the index is standardized). The mussel recruitment data were collected at approximately $44^{\circ} \mathrm{N}, 124^{\circ} \mathrm{W}$ (red dot in panels b and c). (b) Difference in satellite sea surface height (SSH) between the periods 2000-2006 and 1990-1999 (shaded colors) and mean SSH (black contours). The strong dipole of SSH in the northeast Pacific indicates an intensification of the North Pacific Current and its branches along the eastern boundary (red arrows), which is consistent with the positive phase of the NPGO. (c) Same as (b) for the NOAA sea surface temperatures (SST) (Smith and Reynolds 2004). The SST pattern difference is also strongly correlated with the Victoria Mode (Bond et al. 2003), which is the SST expression of the NPGO.

$\mathrm{CM}$ and $\mathrm{FC}$ together but separated from $\mathrm{BB}$; the southern site CA with the northern site BB; Fig. S3). With the complex mix of climate influences, and the range of broad coherence among all sites in some years (1999) to these more local-scale idiosyncratic groupings, it seems clear that phytoplankton patterns at a site are a function of a spectrum of influences (currents, upwelling, perhaps local coastal geomorphology) that vary across space and time.

Second, the huge increases in mussel recruitment were associated with the increases in phytoplankton (Figs. 7 and 12) but visual inspection of Figs. 2 and 5 and the scatter of points in Figs. 7 and 12 suggests that high food and the increasing NPGO were only part of the explanation of increased recruitment. Other potential mechanisms include those related to larval transport and post-settlement mortality or enhanced survival in the collectors. Upwelling is known to influence barnacle recruitment (e.g., Farrell et al. 1991, Shkedy and
Roughgarden 1997, Dudas et al. 2009) and likely mussel recruitment (e.g., Rilov et al. 2008), so we examined patterns of upwelling across the 1989-2007 time frame of our data sets at latitudes that bracket our region. Inspection of the data (Appendix B: Fig. B4) indicates that the hypothesis of an association between upwelling and the greatly increased mussel recruitment in the 2000 s is not supported. Mean monthly upwelling in 2000-2007 was not different from that in 1989-1999 at either latitude (one-way ANOVA; $45^{\circ} \mathrm{N} \mathrm{P}=0.71,42^{\circ} \mathrm{N}$ $P=0.16$ ). We note however that the Bakun index may not be the best reflection of upwelling where it matters for intertidal organisms, in the very inner shelf waters from 0 to 2 or $3 \mathrm{~km}$ from the shore. The Bakun index is a relatively coarse measure (pixel size is $1^{\circ}$ or a rectangle of $180 \times 360 \mathrm{~km}$ ) and probably best reflects upwelling conditions occurring somewhat further offshore.

As with phytoplankton, mussel recruitment also varied in a complex way in space and time. In terms of 


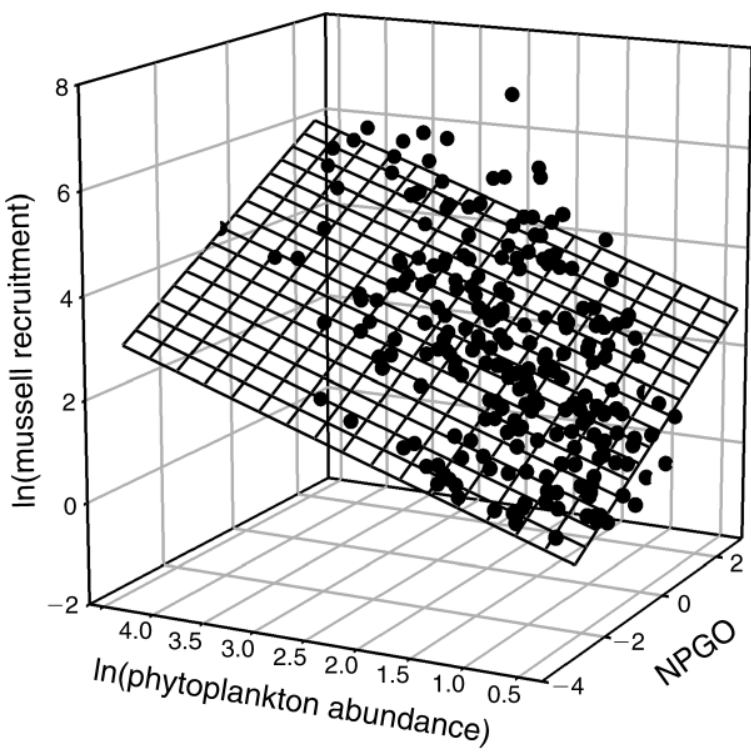

FIG. 12. Relationship between NPGO, phytoplankton abundance (measured as $\mu \mathrm{g} \operatorname{chl} a / \mathrm{L}$ ), and mussel recruitment (measured as no. of recruits per day per collector). The regression equation is $\ln$ (mussel recruitment) $=1.22+$ $0.55(\mathrm{NPGO})+0.68\left(\ln [\right.$ phytoplankton] $) ; F_{2,234}=117, P<$ $0.001, R^{2}=0.50, n=237$ data points.

pattern, the sites from TK north were generally similar, and distinct from those at CA and south (Fig. 2). Time series at the southern sites were shorter, but the interdecadal changes at $\mathrm{CA}$, with data extending back to 1995, were minimal, suggesting that inter-decadal increases in mussel recruitment may have been limited to the sites to the north. In terms of magnitude of recruitment, cluster analysis (Appendix B: Fig. B5) identified a lower-recruitment group $(\mathrm{BB}, \mathrm{TK}, \mathrm{CB}, \mathrm{CA}$, and RP) and a higher-recruitment group (CM, FC, SR, $\mathrm{SH}$, and $\mathrm{YB}$ ). As with phytoplankton, these groupings include both geographically adjacent sites $(\mathrm{SH}, \mathrm{YB}$, and $\mathrm{SR}$; $\mathrm{CM}$ and FC) and sites quite distant from each other (BB and TK; CA and RP; FC and SH). Thus, mussel recruitment also appears to vary as a function of a complex combination of large- to local-scale processes. We suggest that the increase in mussel recruitment that began in 2000 and persisted through about 2004 at most sites was primarily a response to the cooler waters and stronger gyre circulation associated with NPGO with additional variability explained by local-scale influences that are as yet undefined (see e.g., Rilov et al. 2008). Exactly how coastal currents and other processes interacted to produce the change, however, awaits more detailed investigation of physical oceanographic data from the inner shelf (e.g., Kirincich et al. 2005).

\section{Community consequences}

Have these changes in phytoplankton and mussel inputs had an influence on rocky intertidal communities? Increased phytoplankton abundance evidently increased mussel recruitment, likely through influencing growth, survival or both, of mussel larvae (Figs. 7 and 12). Higher phytoplankton, interacting with intertidal temperature, has also led to increased growth rates of adult mussels (Menge et al. 2008) and shading by intense coastal phytoplankton blooms can reduce the growth of benthic macrophytes (Kavanaugh et al. 2009). Increased mussel growth is likely to strengthen competition for space with indirect consequences on food supply for predators and competitors for space. Specifically, lateral pressures from faster mussel growth is likely to both elevate the rate at which mussels are pushed down into the low intertidal foraging range of their primary predator, the sea star Pisaster ochraceus, increase the rate of competitive overgrowth of adjacent space occupants, and increase the rate of recovery from disturbance (e.g., Paine 1974, 1984, Paine and Levin 1981, Sousa 2001, Guichard et al. 2003). Thus, bottomup impacts seem likely to have influenced the link between phytoplankton, a key food of many invertebrate zooplankton (Vargas et al. 2006), mussel larvae, and the dynamics of established mussel beds.

Has mussel abundance responded to the increased supply of mussel recruits? As will be reported elsewhere, the short answer is no. First, from regional to near-global scales, abundance of mussels seems generally insensitive to among-site differences in recruitment rate (e.g., Menge et al. 2004, Wieters et al. 2008). Second, and more specifically in Oregon, no persistent temporal change in mussel abundance was observed related to the dramatic increase in mussel recruitment in 2000 and subsequent years (B. A. Menge, F. Chan, K. Nielsen, J. Lubchenco, G. Hudson, M. Foley, and M. Robart, unpublished data). The reason for this lack of response appears to be rooted in species interactions and diversity in dynamical responses. Mussels can be long-lived and potential for population changes may be strongly buffered by storage effects (Warner and Chesson 1985). Alternatively, mussel abundance onshore can be strongly influenced by facilitation from barnacles (Menge 1976, Berlow 1997, 1999). In experiments, increases in mussel abundance are strongly dependent on a high cover of barnacles, which provide rugosity for mussel recruits and juveniles. If barnacles are removed after settlement, mussels do not colonize experimental plots (Menge 1976, Berlow 1997, 1999). As will be detailed elsewhere (B. A. Menge, F. Chan, K. Nielsen, J. Lubchenco, G. Hudson, M. Foley, and M. Robart, unpublished data), a lack of responses in barnacle recruitment comparable to that of mussel recruitment in part may underlie the lack of change in mussel abundance.

\section{Climate impacts on coastal ecosystems}

Phytoplankton and mussel recruitment increased dramatically in the $2000 \mathrm{~s}$, but as summarized above, the impact on coastal ecosystems has thus far been relatively subtle. Are these changes a reflection of climate change? And are we likely to see more or larger 
changes in the near future? At this point, the answer to both is that we don't know. In the short term, the magnitudes of both response variables have in the last few years $(2006,2007)$ moved back to values closer to pre-2000 values, so it is possible that these changes were relatively transient and reflect natural cycles in dominant modes of climate variability. It is important to note, however, that climate modes such as the NPGO may themselves be subject to modulation by anthropogenic climate forcing. For example, climate model projections highlight the potential for increased variance in NPGO under future greenhouse gas emission scenarios (Di Lorenzo et al. 2008). As a result, the sensitivity of innershelf production and mussel recruitment to the NPGO may serve as a key mode of climate-ecosystem linkages in coastal systems. Over longer timescales, climate models generally suggest major but sometimes conflicting future changes in coastal oceanography (Bakun 1990, Vecchi et al. 2006). With other changes, such as hypoxia/anoxia along the Oregon and Washington coast (Grantham et al. 2004, Chan et al. 2008), the responses seen so far off Oregon (phytoplankton concentration, mussel recruitment, mussel growth) have been to critically important components of coastal ecosystems, but so far these systems evidently have been relatively resilient to these changes. Mechanistically, all these changes are linked to a common set of oceanographic changes, including shifts toward stronger upwellingfavorable winds (Diffenbaugh et al. 2003) and cold water intrusions from the subarctic (Peterson and Schwing 2003, Grantham et al. 2004, Chan et al. 2008). These shifts are consistent with model predictions of impacts of climate change on coastal oceans, but we cannot as yet attribute them to climate change. A key question is thus at what ecosystem state will a threshold be reached that will shift the system into a new, alternative state, and how might this be related to climate change? We cannot answer this question either, but believe that investigating the actual mechanisms that underlie the ecosystem responses seen to date may offer valuable insights.

\section{ACKNOWLEDGMents}

We thank our superb technical assistants for their dedicated and skillful efforts in helping to keep these time series going; primary among these have been B. Daley, G. Hudson, M. Foley, J. Pamplin, M. Robart, C. Cardoni, E. Richmond, M. Noble, G. Murphy, and C. Pennington. The efforts of legions of undergraduate interns, too numerous to list, in doing most of the counting are greatly appreciated. The research was supported by funding from NSF, the Andrew W. Mellon Foundation, the Wayne and Gladys Valley Foundation, the David and Lucile Packard Foundation, the Gordon and Betty Moore Foundation, and the Bob and Betty Lundeen Marine Biology Fund. This paper is contribution number 324 from the Partnership for Interdisciplinary Studies of Coastal Oceans (PISCO), a large-scale, long-term consortium with core funding from the David and Lucile Packard Foundation and the Gordon and Betty Moore Foundation. This research was also supported by the Pacific Boundary Ecosystem and Climate project sponsored by NSF-GLOBEC OCE-0815280.

\section{Literature Cited}

Bakun, A. 1990. Global climate change and the intensification of coastal upwelling. Science 247:198-201.

Barth, J. A., B. A. Menge, J. Lubchenco, F. Chan, J. M. Bane, A. R. Kirincich, M. A. McManus, K. J. Nielsen, S. D. Pierce, and L. Washburn. 2007. Delayed upwelling alters nearshore coastal ocean ecosystems in the northern California current. Proceedings of the National Academy of Sciences (USA) 104: 3719-3724.

Bayne, B. L. 1964. Primary and secondary settlement in Mytilus edulis (L. Mollusca). Journal of Animal Ecology 33:513-523.

Bayne, B. L. 1983. Physiological ecology of marine molluscan larvae. Pages 299-343 in N. H. Verdonk, J. A. M. van den Biggelaar, and A. Tompa, editors. The Mollusca: development. Academic Press, New York, New York, USA.

Berlow, E. L. 1997. From canalization to contingency: historical effects in a successional rocky intertidal community. Ecological Monographs 67:435-460.

Berlow, E. L. 1999. Strong effects of weak interactions in ecological communities. Nature 398:330-334.

Bond, N. A., J. E. Overland, M. Spillane, and P. Stabeno. 2003. Recent shifts in the state of the North Pacific. Geophysical Research Letters 30:2183.

Britton-Simmons, K. H., and K. C. Abbott. 2008. Short- and long-term effects of disturbance and propagule pressure on a biological invasion. Journal of Ecology 96:68-77.

Broitman, B. R., C. A. Blanchette, and S. D. Gaines. 2005. Recruitment of intertidal invertebrates and oceanographic variability at Santa Cruz Island, California, USA. Limnology and Oceanography 50:1473-1479.

Broitman, B. R., C. A. Blanchette, B. A. Menge, J. Lubchenco, C. Krenz, M. Foley, P. Raimondi, D. Lohse, and S. D. Gaines. 2008. Spatial and temporal patterns of invertebrate recruitment along the west coast of the United States. Ecological Monographs 78:403-421.

Chan, F., J. A. Barth, J. Lubchenco, A. R. Kirincich, H. Weeks, W. T. Peterson, and B. A. Menge. 2008. Emergence of anoxia in the California Current Large Marine Ecosystem. Science 319:920.

Chatfield, C. 2004. The analysis of time series: an introduction. Chapman and Hall/CRC, Boca Raton, Florida, USA.

Chhak, K., and E. Di Lorenzo. 2007. Decadal variations in the California Current upwelling cells. Geophysical Research Letters 34:L14604.

Connell, J. H. 1985. The consequences of variation in initial settlement vs. post settlement mortality in rocky intertidal communities. Journal of Experimental Marine Biology and Ecology 93:11-45.

Connolly, S. R., B. A. Menge, and J. Roughgarden. 2001. A latitudinal gradient in recruitment of intertidal invertebrates in the northeast Pacific Ocean. Ecology 82:1799-1813.

Connolly, S. R., and J. Roughgarden. 1999. Theory of marine communities: competition, predation, and recruitment-dependent interaction strength. Ecological Monographs 69: 277-296.

Denny, M. W., and R. T. Paine. 1998. Celestial mechanics, sealevel changes, and intertidal ecology. Biological Bulletin 194: $108-115$.

Diaz, R. J. 2001. Overview of hypoxia around the world. Journal of Environmental Quality 30:275-281.

Diaz, R. J., and R. Rosenberg. 2008. Spreading dead zones and consequences for marine ecosystems. Science 321:926-929.

Diffenbaugh, N. S., M. A. Snyder, and L. C. Sloan. 2003. Could $\mathrm{CO}_{2}$-induced land-cover feedbacks alter near-shore upwelling regimes? Proceedings of the National Academy of Sciences (USA) 101:27-31.

Di Lorenzo, E., N. Schneider, K. M. Cobb, K. Chhak, P. J. S. Franks, A. J. Miller, J. C. McWilliams, S. J. Bograd, H. Arango, E. Curchister, T. M. Powell, and P. Rivere. 2008. 
North Pacific Gyre Oscillation links ocean climate and ecosystem change. Geophysical Research Letters 35:L08607.

Duarte, C. M., J. Cebrian, and N. Marba. 1992. Uncertainty of detecting sea change. Nature 356:190.

Dudas, S. E., B. A. Grantham, A. R. Kirincich, B. A. Menge, J. Lubchenco, and J. A. Barth. 2009. Current reversals as determinants of intertidal recruitment on the central Oregon coast. ICES Journal of Marine Science 66:396-407.

Farrell, T. M., D. Bracher, and J. Roughgarden. 1991. Crossshelf transport causes recruitment to intertidal populations in central California. Limnology and Oceanography 36:279288.

Foster, B. L., and T. L. Dickson. 2004. Grassland diversity and productivity: the interplay of resource availability and propagule pools. Ecology 85:1541-1547.

Francis, R. C., S. R. Hare, A. B. Hollowed, and W. S. Wooster. 1998. Effects of interdecadal climate variability on the oceanic ecosystems of the Northeast Pacific. Fisheries Oceanography 7:1-21.

Gaines, S. D., and J. Roughgarden. 1985. Larval settlement rate: a leading determinant of structure in an ecological community of the marine intertidal zone. Proceedings of the National Academy of Sciences (USA) 82:3707-3711.

Graham, W. M., and J. L. Largier. 1997. Upwelling shadows as nearshore retention sites: the example of northern Monterey Bay. Continental Shelf Research 17:509-532.

Grantham, B. A., F. Chan, K. J. Nielsen, D. S. Fox, J. A. Barth, A. Huyer, J. Lubchenco, and B. A. Menge. 2004. Upwelling-driven nearshore hypoxia signals ecosystem and oceanographic changes in the Northeast Pacific. Nature 429: $749-754$.

Guichard, F., P. Halpin, G. W. Allison, J. Lubchenco, and B. A. Menge. 2003. Mussel disturbance dynamics: signatures of oceanographic forcing from local interactions. American Naturalist 161:889-904.

Harley, C. D. G., A. R. Hughes, K. M. Hultgren, B. G. Miner, C. J. B. Sorte, C. S. Thornber, L. F. Rodriguez, L. Tomanek, and S. L. Williams. 2006. The impacts of climate change in coastal marine systems. Ecology Letters 9:228-241.

Kavanaugh, M., K. J. Nielsen, F. Chan, B. A. Menge, R. M. Letelier, and L. M. Goodrich. 2009. Experimental assessment of the effects of shade on an intertidal kelp: do phytoplankton blooms inhibit growth of open-coast macroalgae? Limnology and Oceanography 54:276-288.

Kirincich, A. R., J. A. Barth, B. A. Grantham, J. Lubchenco, and B. A. Menge. 2005. Wind-driven inner-shelf circulation off central Oregon during summer. Journal of Geophysical Research 110:C10S03.

Leonard, G. H., J. M. Levine, P. R. Schmidt, and M. D. Bertness. 1998. Flow-driven variation in intertidal community structure in a Maine estuary. Ecology 79:1395-1411.

Leslie, H., E. N. Breck, F. Chan, J. Lubchenco, and B. A. Menge. 2005. Hotspots of barnacle reproduction associated with nearshore ocean conditions. Proceedings of the National Academy of Sciences (USA) 102:10534-10539.

Lutz, R. A., and M. J. Kennish. 1992. Ecology and morphology of larval and early postlarval mussels. Pages 53-85 in E. Gosling, editor. The mussel Mytilus: ecology, physiology, genetics and culture. Elsevier, Amsterdam, The Netherlands.

Martel, A. L., C. Robles, K. Beckenbach, and M. J. Smith. 1999. Distinguishing early juveniles of eastern Pacific mussels (Mytilus spp.) using morphology and genomic DNA. Invertebrate Biology 118:149-164.

Menge, B. A. 1976. Organization of the New England rocky intertidal community: role of predation, competition and environmental heterogeneity. Ecological Monographs 46: $355-393$.

Menge, B. A. 2000. Top-down and bottom-up community regulation in marine rocky intertidal habitats. Journal of Experimental Marine Biology and Ecology 250:257-289.
Menge, B. A., E. L. Berlow, C. A. Blanchette, S. A. Navarrete, and S. B. Yamada. 1994. The keystone species concept: variation in interaction strength in a rocky intertidal habitat. Ecological Monographs 64:249-286.

Menge, B. A., C. A. Blanchette, P. Raimondi, T. L. Freidenburg, S. D. Gaines, J. Lubchenco, D. Lohse, G. Hudson, M. M. Foley, and J. Pamplin. 2004. Species interaction strength: testing model predictions along an upwelling gradient. Ecological Monographs 74:663-684.

Menge, B. A., F. Chan, and J. Lubchenco. 2008. Response of a rocky intertidal ecosystem engineer and community dominant to climate change. Ecology Letters 11:151-162.

Menge, B. A., B. A. Daley, J. Lubchenco, E. Sanford, E. Dahlhoff, P. M. Halpin, G. Hudson, and J. L. Burnaford. 1999. Top-down and bottom-up regulation of New Zealand rocky intertidal communities. Ecological Monographs 69: 297-330.

Menge, B. A., B. A. Daley, P. A. Wheeler, and P. T. Strub. 1997. Rocky intertidal oceanography: an association between community structure and nearshore phytoplankton concentration. Limnology and Oceanography 42:57-66.

Menge, B. A., J. Lubchenco, M. E. S. Bracken, F. Chan, M. M. Foley, T. L. Freidenburg, S. D. Gaines, G. Hudson, C. Krenz, H. Leslie, D. N. L. Menge, R. Russell, and M. S. Webster. 2003. Coastal oceanography sets the pace of rocky intertidal community dynamics. Proceedings of the National Academy of Sciences (USA) 100:12229-12234.

Menge, B. A., and J. P. Sutherland. 1987. Community regulation: variation in disturbance, competition, and predation in relation to environmental stress and recruitment. American Naturalist 130:730-757.

Millenium Ecosystem Assessment. 2005. Ecosystems and human well-being: synthesis. Island Press, Washington, D.C., USA.

Minchinton, T. E., and R. E. Scheibling. 1991. The influence of larval supply and settlement on the population structure of barnacles. Ecology 72:1867-1879.

Navarrete, S. A., B. R. Broitman, and B. A. Menge. 2008. Interhemispheric comparison of recruitment to intertidal communities: pattern persistence and scales of variation. Ecology 89:1308-1322.

Navarrete, S. A., B. R. Broitman, E. A. Wieters, and J. C. Castilla. 2005. Scales of benthic-pelagic coupling and the intensity of species interactions: from recruitment limitation to top down control. Proceedings of the National Academy of Sciences (USA) 102:18046-18051.

Navarrete, S. A., and B. A. Menge. 1996. Keystone predation and interaction strength: interactive effects of predators on their main prey. Ecological Monographs 66:409-429.

Navarrete, S. A., B. A. Menge, and B. A. Daley. 2000. Species interactions in intertidal food webs: prey or predation regulation of intermediate predators? Ecology 81:2264-2277.

O'Riordan, R. M., et al. 2004?. Spatial variation in the recruitment of the intertidal barnacles Chthamalus montagui Southward and Chthamalus stellatus (Poli) (Crustacea: Cirripedia) over a European scale. Journal of Experimental Marine Biology and Ecology 304:243-264.

Paine, R. T. 1971. A short-term experimental investigation of resource partitioning in a New Zealand rocky intertidal habitat. Ecology 52:1096-1106.

Paine, R. T. 1974. Intertidal community structure: experimental studies on the relationship between a dominant competitor and its principal predator. Oecologia 15:93-120.

Paine, R. T. 1984. Ecological determinism in the competition for space. Ecology 65:1339-1348.

Paine, R. T., and S. A. Levin. 1981. Intertidal landscapes: disturbance and the dynamics of pattern. Ecological Monographs 51:145-178.

Paine, R. T., and A. C. Trimble. 2004. Abrupt community change on a rocky shore: biological mechanisms contributing 
to the potential formation of an alternative state. Ecology Letters 7:441-445.

Parmesan, C. 2006. Ecological and evolutionary responses to recent climate change. Annual Review of Ecology, Evolution, and Systematics 37:637-669.

Parmesan, C., and G. Yohe. 2003. A globally coherent fingerprint of climate change impacts across natural systems. Nature 421:37-42.

Peterson, W. T., and F. B. Schwing. 2003. A new climate regime in northeast Pacific ecosystems. Geophysical Research Letters 30:1896.

Pineda, J. 1999. Circulation and larval distribution in internal tidal bore warm fronts. Limnology and Oceanography 44: 1400-1414.

Pineda, J., J. A. Hare, and S. Sponaugle. 2007. Larval transport and dispersal in the coastal ocean and consequences for population connectivity. Oceanography 20:22-39.

Porri, F., C. D. McQuaid, and S. Radloff. 2006. Spatiotemporal variability of larval abundance and settlement of Perna perna: differential delivery of mussels. Marine Ecology Progress Series 315:141-150.

Rabalais, N. N., R. E. Turner, and W. J. Wiseman, Jr. 2001. Hypoxia in the Gulf of Mexico. Journal of Environmental Quality 30:320-329.

Richardson, A. J., and E. S. Poloczanska. 2008. Underresourced, under threat. Science 320:1294-1295.

Rilov, G., S. E. Dudas, B. A. Menge, B. A. Grantham, J. Lubchenco, and D. R. Schiel. 2008. The surf zone: a semipermeable barrier to onshore recruitment of invertebrate larvae? Journal of Experimental Marine Biology and Ecology 361:59-74.

Sagarin, R. D., J. P. Barry, S. E. Gilman, and C. H. Baxter. 1999. Climate-related change in an intertidal community over short and long time scales. Ecological Monographs 69:465-490.

SAS Institute. 2007. JMP, release 7. SAS Institute, Cary, North Carolina, USA.

Shaffer, G., S. M. Olsen, and J. O. P. Pedersen. 2009. Longterm ocean oxygen depletion in response to carbon dioxide emissions from fossil fuels. Nature Geoscience 2:105-109.

Shanks, A. L., and L. Brink. 2005. Upwelling, downwelling, and cross-shelf transport of bivalve larvae: test of a hypothesis. Marine Ecology Progress Series 302:1-12.

Shkedy, Y., and J. Roughgarden. 1997. Barnacle recruitment and population dynamics predicted from coastal upwelling. Oikos 80:487-498.

Smith, J. R., P. Fong, and R. F. Ambrose. 2006. Dramatic declines in mussel bed community diversity: response to climate change? Ecology 87:1153-1161.

Smith, T. M., and R. W. Reynolds. 2004. Improved extended reconstruction of SST (1854-1997). Journal of Climatology 17:2466-2477.
Sousa, W. P. 2001. Natural disturbance and the dynamics of marine benthic communities. Pages $85-130$ in M. D. Bertness, S. D. Gaines, and M. E. Hay, editors. Marine community ecology. Sinauer Associates, Sunderland, Massachusetts, USA.

Strathmann, M. F. 1987. Reproduction and development of marine invertebrates of the Northern Pacific Coast. University of Washington Press, Seattle, Washington, USA.

Tapia, F. J., J. Pineda, F. Ocampo-Torres, H. Fuchs, E. Parnell, P. Montero, and S. Ramos. 2004. High-frequency observations of wind-forced onshore transport at a coastal site in Baja California. Continental Shelf Research 24:15731585.

Underwood, A. J., and E. J. Denley. 1984. Paradigms, explanations, and generalizations in models for the structure of intertidal communities on rocky shores. Pages 151-180 in D. R. J. Strong, D. Simberloff, L. G. Abele, and A. B. Thistle, editors. Ecological communities: conceptual issues and the evidence. Princeton University Press, Princeton, New Jersey, USA.

Vargas, C. A., P. H. Manriquez, and S. A. Navarrete. 2006. Feeding by larvae of intertidal invertebrates: assessing their position in pelagic food webs. Ecology 87:444-457.

Vecchi, G. A., B. J. Soden, A. T. Wittenberg, I. M. Held, A. Leetmaa, and M. J. Harrison. 2006. Weakening of tropical Pacific atmospheric circulation due to anthropogenic forcing. Nature 441:73-76.

Warner, R. R., and P. L. Chesson. 1985. Coexistence mediated by recruitment fluctuations: a field guide to the storage effect. American Naturalist 125:769-787.

Wheeler, P. A., A. Huyer, and J. Fleischbein. 2003. Cold halocline, increased nutrients, and higher chlorophyll off Oregon in 2002. Geophysical Research Letters 30:8021.

Wieters, E. A., S. D. Gaines, S. A. Navarrete, C. A. Blanchette, and B. A. Menge. 2008. Scales of dispersal and the biogeography of marine predator-prey interactions. American Naturalist 171:405-417.

Wieters, E. A., D. M. Kaplan, S. A. Navarrete, A. Sotomayor, J. L. Largier, K. J. Nielsen, and F. Veliz. 2003. Alongshore and temporal variability in chlorophyll $a$ concentration in Chilean nearshore waters. Marine Ecology Progress Series 249:93-105.

Wilkerson, F. P., and R. C. Dugdale. 1987. The use of large shipboard barrels and drifters to study the effects of coastal upwelling on phytoplankton dynamics. Limnology and Oceanography 32:368-382.

Wolter, K. 1987. The Southern Oscillation in surface circulation and climate over the tropical Atlantic, Eastern Pacific, and Indian Oceans as captured by cluster analysis. Journal of Climate Applied Meteorology 26:540-558.

\section{APPENDIX A}

Five tables analyzing temporal patterns of mussel recruitment, temporal patterns of chlorophyll $a$, univariate analyses of effect of climate patterns on mussel recruitment and chlorophyll $a$, multiple regressions of effects of climate patterns on mussel recruitment and chlorophyll $a$, and linear regressions among the different climate patterns (Ecological Archives M079-013-A1).

\section{APPENDIX B}

Five figures showing variation in average tide height of mussel recruit collectors, relationship between mussel recruitment and sea level, cluster analysis of similarity of chlorophyll $a$ among sites, Bakun upwelling indices from 1989-2007, and cluster analysis of similarity of mussel recruitment among sites (Ecological Archives M079-013-A2). 